\title{
AGAINST THE DISTINCTION BETWEEN INTENTIONS FOR THE FUTURE AND INTENTIONS FOR THE PRESENT
}

\section{Author(s): Chiara Brozzo}

Source: American Philosophical Quarterly, OCTOBER 2021, Vol. 58, No. 4 (OCTOBER 2021), pp. 333-346

Published by: University of Illinois Press on behalf of the North American Philosophical Publications

Stable URL: https://www.jstor.org/stable/10.2307/48619318

\section{REFERENCES}

Linked references are avalable-on TSTOR for this article:
reference\#references_tab_contents
You may need to log in to JSTOR to access the linked references.

JSTOR is a not-for-profit service that helps scholars, researchers, and students discover, use, and build upon a wide range of content in a trusted digital archive. We use information technology and tools to increase productivity and facilitate new forms of scholarship. For more information about JSTOR, please contact support@jstor.org.

Your use of the JSTOR archive indicates your acceptance of the Terms \& Conditions of Use, available at https://about.jstor.org/terms 


\title{
AGAINST THE DISTINCTION BETWEEN INTENTIONS FOR THE FUTURE AND INTENTIONS FOR THE PRESENT
}

\author{
Chiara Brozzo
}

\begin{abstract}
How should we account for the planning and performance of a bodily action in terms of the agent's intentions? An influential answer invokes two distinct kinds of intention: intentions for the future (also known as prior intentions or distal intentions), responsible for action planning, and intentions for the present (also known as intentions in action or proximal intentions), responsible for action performance. I argue that there is something wrong with this influential answer: the notion of intention for the present is either superfluous (because intentions for the future can exercise functions associated both with action planning and with action performance) or ambiguous (because it conflates temporal, functional, and content-related aspects). Developing this criticism will lead to an alternative account of action planning and performance based on intentions of just one kind.
\end{abstract}

\section{INTRODUCTION}

Suppose that someone is sitting in an assembly in which a vote is about to be cast by a show of hands. They resolve to vote in favor of the proposed motion, and, accordingly, they proceed to raise their hand when the appropriate time comes. How is this scenario to be accounted for in terms of the intentions that they possess?

The standard response to this question, given by number of theorists (e.g., Searle 1983; Brand 1984; Bratman 1987; Mele 1992; Pacherie 2006), is that this person should be ascribed two distinct token intentions of different kinds. First, upon settling on the course of action to vote in favor of the motion, they would form an intention for the future representing this course of action. From just before action onset ${ }^{1}$ onwards, this intention would be supplemented by another token intention of a different kind-namely an intention for the present-that initiates the action and sustains it until completion. According to some versions of the standard response, this intention has a content that is more detailed than that of the intention for the future. In the voting scenario mentioned at the outset, it would represent, for example, raising one's hand rather than voting in favor of the motion. Theories that provide this standard response will be referred to as Dual Theories.

The first aim of this article is to raise a problem with Dual Theories - specifically, with the notion of intention for the present. This notion has been widely influential, both in philosophy (e.g., O'Shaughnessy 1991; McDowell 2011; Nanay 2012; Shepherd 2019) and beyond (e.g., Jacob and Jeannerod 2005; Jeannerod 2006; Becchio et al. 2012). Yet, I 
will argue that this notion is either superfluous or ambiguous. This first aim dovetails with a second one: introducing what I shall call the Hierarchical Theory as an alternative to Dual Theories. I will show how the Hierarchical Theory avoids the criticisms that I level against Dual Theories.

\section{What Are Intentions?}

Let me start by saying something about intentions of any kind. ${ }^{2}$ Intentions are mental states representing states of affairs with a world-to-mind direction of fit (Searle 1983; see also Anscombe 1957). This means that, for an intention to be fulfilled, the world should conform to what is represented by the intention. This direction of fit does not exhaust the characterization of intentions, because it equally applies to desires to do something: for a desire to be fulfilled, the world needs to conform to what is represented by the desire. What, then, distinguishes intention from desire? One influential view is that, differently from desiring to do something, intending to do something involves being settled on a certain course of action (Bratman 1984, 1987; Mele 1992; Holton 2009). For example, unlike desiring to catch a specific bus (e.g., bus number 3 at 3:10 p.m.), intending to catch that bus involves being committed to this course of action. Consequently, intending to perform actions that are known to be incompatible with catching that bus (e.g., faffing around until 3:15 p.m.) leads to a charge of irrationality against the subject. By contrast, desiring incompatible courses of action does not.

To be more precise, according to Bratman (1984), any of a subject's intentions should satisfy some consistency constraints. First, a subject's intention should be consistent with the other intentions that the subject has (that is, a subject's intentions should be weakly consistent). Moreover, this intention should be consistent with the subject's beliefs (that is, a subject's intentions should be strongly consistent, relative to the subject's beliefs). When a subject's intentions do not fulfil these consistency constraints-for example, because the subject knowingly holds incompatible intentions - then that subject is guilty of irrationality.

\section{Dual Theories in Broad Outline}

I shall now present the central idea of Dual Theories of intention. Consider $t_{1}$, the timespan running from settling on a certain course of action up to just before action onset, and $t_{2}$, the timespan running from just before action onset to action's end. According to Dual Theories, different kinds of intention should be held at $t_{1}$ and at $t_{2}$. I shall refer to those held at $t 1$ as intentions for the future-versions of which have also been called prior intentions (Searle 1983), prospective intentions (Brand 1984), future-directed intentions (Bratman 1987), distal intentions (Mele 1992; Pacherie 2008; Mylopoulos and Pacherie 2017) — and to those held at $t_{2}$ as intentions for the present-versions of which have been called intentions in action (Searle 1983), immediate intentions (Brand 1984), present-directed intentions (Bratman 1987), proximal intentions (Mele 1992; Pacherie 2008; Mylopoulos and Pacherie 2017). ${ }^{3}$ The central idea shared across most Dual Theories is that intentions for the future and intentions for the present have different functions. Specifically, intentions for the future have functions associated with planning an action, whereas intentions for the present have functions associated with the execution of an action. Let us call such functions planning and executive functions (following Mele 1992 and Pacherie 2006), respectively.

In what do planning functions consist? This is best answered by reference to Michael Bratman (1987), who proposed that the role of intentions in a subject's cognitive economy is to enable effective planning. In line with this idea, his view is that intentions (i) end deliberation, (ii) produce further intentions by 
way of means-end reasoning, and (iii) support coordination (both with the rest of one's plans and with those of other individuals). Intentions end deliberation in the sense that one forms or acquires an intention once they have settled on a certain course of action, and having an intention representing that course of action prevents reconsideration of it. This does not hold for information that one did not possess at the time of deliberation: if, once the subject in our opening example has formed the intention to vote "yes" in a few minutes, they suddenly hear that the building is on fire, they may well give up this intention in favor of that to run out of the building.

The characteristics of intentions for the future according to Bratman are explicitly endorsed by Mele (1992), Pacherie (2008), Mylopoulos and Pacherie (2017). While not mentioning these specific characteristics, Searle (1983) does acknowledge that his version of intentions for the future (prior intentions) have a role in planning, which is fulfilled before action performance.

So much about planning functions. What about executive functions? These are functions associated with the execution of an action-hence their name (Mele 1992; Shepherd 2015). They consist in representing a certain course of action, and moving the subject to bring about that course of action, on the basis of how it is represented. ${ }^{4}$ Mental states with executive functions are thus not only representational (Mele 1992) or cognitive (Brand 1984), but also executive (Mele 1992) or conative (Brand 1984). To be more specific, moving a subject to bring about a certain course of action consists in triggering that course of action and sustaining it until completion.

I have now presented the main motivation for distinguishing two different kinds of intention-intentions for the future and intentions for the present. In the following section, I will show that, working only on the assumption of a difference in function, the notion of intention for the present is superfluous.

\section{The Notion of Intention FOR THE PRESENT Is SuperfluOUS}

I will demonstrate that, given certain assumptions, the notion of intention for the present is superfluous by considering two varieties of Dual Theories in turn: those according to which intentions for the future and intentions for the present have the same content (section 4.1), and those according to which they have different contents (section 4.2).

\subsection{First Variety: Intentions for the Future and Intentions for the Present Have the Same Content}

The most prominent version of a Dual Theory according to which intentions for the future and intentions for the present have the same content is Al Mele's (1992). His version of intentions for the present are proximal intentions - so called because of their temporal proximity to action onset. Proximal intentions exercise executive functions in the following way: whenever the appropriate time for acting comes, a proximal intention triggers the relevant actional mechanisms - a term borrowed from Alston (1974) that stands for whatever in the brain's motor system is responsible for the production of bodily movements (Mele 1992, pp. 180-181) — and sustains them until action completion. Assuming that a subject already has an intention for the future, Mele's version of the corresponding intention for the present inherits its content from the intention for the future, moves the subject to perform the action according to how the latter is represented in the content, and sustains that action until completion. Working on these assumptions, I am now going to challenge the idea that two token intentions of different kinds are needed to account for this sort of scenario.

My argument is going to be based on a general feature of propositional attitudes: these 
can acquire motivational force as a function of time, assuming that their subject can keep track of time (see Evans 1982). For example, suppose one forms an intention expressed by the sentence $S_{1}$ : "I intend to raise my arm in 10 minutes." After 10 minutes, they will have realized that the time for acting has come, and the same token intention as the one expressed by the sentence $S_{1}$ will now be expressed by $S_{2}$ : "I intend to raise my arm now." This change in expression reflects a change in the motivational force of the intention. In virtue of the subject's realization that 10 minutes have passed, this subject's intention will acquire a motivational force that makes it apt to initiate an action (for example, by activating the relevant actional mechanisms - it being a further question exactly how this happens). The same principle accounts for this very intention sustaining the action until completion-for example, until the subject realizes that the meeting is over. This does not require positing an additional token intention, let alone an additional kind of intention (see McDowell 2011 for a similar line of argument). ${ }^{6}$

This conclusion makes all the more sense if one considers an analogy between intentions on the one hand and combinations of beliefs and desires on the other hand. Some combinations of beliefs and desires have different functions at different times: for instance, a belief that one has an appointment at 3 p.m. combined with the desire to go to that appointment provide one with the motivation to go to the appointment once the relevant time comes. Yet, no additional kind of desire-say, executive desire or desire in action-is ever posited to take care of the additional motivating function that this desire has from the relevant time onwards, combined with the belief that one has an appointment at 3 p.m. (see Sinhababu 2013).

Now, bearing the previous reflections in mind, of course we are free to subdivide a single token intention into its temporal components, which we may then call intention for the future and intention for the present. But it is unclear why we should consider the intention for the future and the intention for the present as being of different kinds, rather than, simply, different temporal segments of the same token intention.

Let me take stock. In this section, I have worked on the assumption that intentions for the future and intentions for the present have the same content and different functions-in particular, that intentions for the future exercise planning functions until just before action onset and intentions for the present exercise executive functions from just before action onset until action completion. I have argued that this may be accounted for by just one token intention, which, just by virtue of its persistence in time, is apt to exercise executive functions, in addition to planning functions, from a certain point onwards. Therefore, the notion of intention for the present is superfluous.

\subsection{Second Variety: Intentions for the \\ Future and Intentions for the Present Have Different Contents}

At this point, one may suspect that, perhaps, the notion of intention for the present is only superfluous if we assume, as we did in the previous section, that this intention has the same content as an intention for the future. What if we work on a different assumption, namely that intentions for the future and intentions for the present have different contents? Specifically, what if we assume that an intention for the present has a more detailed content than an intention for the future (Searle 1983; Brand 1984; Pacherie 2006; Mylopoulos and Pacherie 2017)? Does it then become more plausible that we should distinguish two kinds of intentions on functional grounds? I will show that, even in this case, the notion of intention for the present is superfluous.

The first step of my argument will be to establish that intentions for the future, unless revoked or abandoned by a subject, last until 
action completion. The result of this first step will be that intentions for the future overlap with intentions for the present between just before action onset and action completion.

O'Shaughnessy (1991) provides an instructive example to this effect: suppose that on Monday I decide to swim the English Channel at 6 a.m. on Tuesday. I thus form an intention for the future that lasts at least until that time. What then? Does this intention suddenly expire? O'Shaughnessy rightly suggests that it will not, until I have finished crossing the Channel (unless I change my mind and abandon the feat). For, "[d]elete the intention at any point and the act fizzles out [ . . .]" (O'Shaughnessy 1991, pp. 273-274; see also Mele 1992; Pacherie 2008). In other words, without that intention I would no longer have the motivation to keep swimming, and would thereby put an end to my action-for instance, "join my friends in the boat” (O'Shaughnessy 1991, p. 274). Therefore, the intention for the future to swim the Channel must persist until action's end. If an intention for the present with a more specific content is formed closer to action initiation, then the two token intentions will both persist until action's end.

At this point, one may wonder whether the persisting intention for the future to swim the Channel is different from the intention for the present with a more specific content. I suggest that it is, because these two token intentions represent different states of affairs. A subject's intentions reflect what state (or states) of affairs the subject is committed to. A subject might be simultaneously committed to different states of affairs, and different token intentions will reflect that. For example, suppose someone has an intention with a given content-say, to go to a concert. Suppose, further, that they settle on specific means for achieving that end-say, going by horse-drawn carriage. In most situations, that one settles on specific means to achieve an end (e.g., going by horse-drawn carriage) does not make it any less true that one also intends to bring about that end (going to the concert), regardless of the means they end up settling upon. That is, one is committed to bringing about both states of affairs - the end regardless of the means, as well as the specific chosen means. But contrast the scenario just considered with one in which someone intends to go to a concert by horse-drawn carriage, and in no other way. This case is captured by the subject's having the intention to go to the concert by horse-drawn carriage, but not by their having both the intention to go to the concert by horse-drawn carriage and the intention to go to the concert, because they are not committed to the latter state of affairs ("If we are not going by horse-drawn carriage, don't even bother to turn up!"). The idea that the intention to go to the concert is a different token intention from that to go to the concert by horse-drawn carriage enables us to distinguish the commitments of the accommodating subject in the first scenario from those of the fastidious subject in the second scenario (see also Holton 2009).

If we want to do justice to these differential commitments, as we should, we can conclude that intentions for the future, unless revoked by the subject, last until action completion, alongside intentions for the present (see also Searle 1991 in response to O'Shaughnessy 1991; Mele 1992; Pacherie 2008).

At this point, it has been established that intentions for the future and intentions for the present, assuming that they have different contents, both last until action completion (unless either is revoked). Working on this assumption, can a distinction between intentions for the future and intentions for the present be retained on functional grounds? I will argue for a negative answer, by showing that each intention has both kinds of function.

Let me start with intentions for the future. So far, I have shown that they last until action completion. In the previous section, I showed that, if an intention lasts until 
action completion, then it will have executive functions from just before action onset onwards-assuming that the subject can keep track of time. My interim conclusion is therefore that intentions for the future, besides planning functions, also have executive functions.

Conversely, it can be shown that intentions for the present also have planning functions - that is, ending deliberation, generating new intentions by means-end reasoning, and supporting coordination. Consider the intention for the present to swim with the breaststroke technique. Here is how it may end deliberation even while the action is being performed. Recall from section 3 that deliberation is ended relative to a certain body of information. If the subject acquires new information, deliberation can be re-opened. The unfolding of an action is precisely the sort of circumstance that could potentially provide a subject with new informationfor example, by starting to swim with the breaststroke technique, I may realize that I am getting tired much earlier than I expected. This new piece of information might lead me to re-open deliberation. Notice that any point during the crossing may provide me with new information, so that at any point I may in principle re-open deliberation. Therefore, at any point after action onset, an intention for the present has the potential of ending deliberation. Moreover, the intention for the present may also generate new token intentions via means-end reasoning (e.g., the intention to move one's arms in a certain way), as well as support coordination by suitably constraining the content of any newly formed intention. In other words, intentions for the present, too, have planning functions in addition to executive functions. This is in line with the idea that, as has been independently observed by Bratman (1987), Pacherie (2008) and Shepherd (2015), the exercise of planning functions is not over once the action has started.
So, working on the assumption that intentions for the future and intentions for the present differ in content, the idea that they should be differentiated on the grounds that they have different functions does not stand up to scrutiny: I have shown that intentions for the future have executive functions alongside planning functions, and that intentions for the present have planning functions alongside executive functions. ${ }^{7}$ So, even in this case, the notion of intention for the present is superfluous.

\section{The Notion of Intention for the Present Is Ambiguous}

I have just reviewed a main motivation for distinguishing intentions for the future from intentions for the present. I have shown that, working merely on the assumption of a difference in function, the notion of intention for the present is superfluous. Now I shall review two additional main motivations for distinguishing between intentions for the future and intentions for the present. The first, which I will discuss in section 5.1, is that closeness to action onset, when intentions for the present are allegedly formed, makes it the case that the content of intentions for the present is more specific than that of intentions for the future. The second, which I will discuss in section 5.2, is that the exercise of executive functions requires intentions for the present to have a certain kind of content. I shall argue that both ideas are mistaken, and lead to an ambiguous notion of intention for the present, insofar as it conflates temporal, functional, and contentrelated aspects.

\subsection{Does Proximity to Action Onset \\ Require a More Detailed Content?}

Some Dual Theories have it that intentions for the future should be differentiated from intentions for the present on the grounds that the latter, in virtue of being formed closer to action onset, will have a more detailed content 
than the former. Searle, for example, has suggested that:

[i]n any real-life situation the [intention for the present] will be much more determinate than the [intention for the future], it will include not only that my arm goes up but that it goes up in a certain way and at a certain speed, etc. (1983, p. 93)

This leads to a conflation between temporal and content-related aspects: intentions for the present are characterized both in terms of being formed just before action onset (temporal aspect) and in terms of having a more specific content than intentions for the future (content-related aspect). However, the conflation between temporal and contentrelated aspects should be avoided: as has been observed even in the context of some Dual Theories (e.g., Pacherie 2006; Mylopoulos and Pacherie 2018), one may represent an action in greater detail at any point in time, before or after action onset. Thus, the notion of intention for the present is ambiguous: it is often not clear whether it is an intention formed in proximity to action onset, or an intention with a very specific content, or both.

The idea that intentions for the present have a more detailed content than intentions for the future renders the notion of intention for the present ambiguous also in another respect. The representation of an action in greater detail is not a one-time phenomenon: one can represent the action that one is going to perform (or is performing) in greater detail not only at any point in time, but also as many times as one wishes. This makes it hard to understand which intentions should count as intentions for the present on content-related grounds, as I will now show.

Think again of the Channel-swimming example. After beginning to act (i.e., after diving into the Channel), I have multiple chances for forming new intentions. For example, I may form the intention to swim around an obstacle. This is an intention with a more detailed content than that of swimming the
Channel, and, as such, it may be considered an intention for the present on content-related grounds. The intention to swim around an obstacle, however, may in turn generate the intention to swim around the obstacle with the breaststroke technique, which is an intention with an even more detailed content than that of swimming around the obstacle. As such, it should be an intention for the present. What about the intention to swim around the obstacle, then? Should it be an intention for the future, insofar as it has a less detailed content than the intention to swim around the obstacle with the breaststroke technique? Or an intention for the present, insofar as it has a more detailed content than the intention to swim the Channel? There is no principled answer to this question: the fact that a subject will normally form many new token intentions with a more detailed content, and not just one, makes it hard to draw a distinction between intentions for the future and intentions for the present based on the extent to which their content is detailed. This is another respect in which the notion of intention for the present is ambiguous. ${ }^{8}$

\subsection{Does the Exercise of Executive Functions Require a Certain Kind of Content?}

Another motivation in support of the distinction between two kinds of intention is the idea that intentions for the present need to have a very detailed content, because this is necessary for the performance of executive functions. However, it can be shown that it is not.

Consider the following example.

Wilma, standing at a bus stop, sees a baby leaning out of a fourth-story window and feels certain that he will fall. We may suppose that Wilma proximally intends to save the baby and that she immediately begins running toward him with that intention, though her plan for saving the baby is not yet fully determinate. As Wilma runs, the details fall into place [...]. But there was a time, however brief, during which she 
was settled upon saving the child without yet being settled upon the precise manner in which she would save him. (Mele 1992, p. 178, my emphasis)

This example shows that an intention held in proximity of action onset or during action performance may have a content that is not very detailed (i.e., not specifying the manner in which Wilma will save the baby), and yet exercise executive functions - that is, it is apt to trigger a certain course of action and sustain it until completion. So, the exercise of executive functions does not require that the intention exercising this function should have a content that is very detailed.

An alternative motivation for preserving the distinction between two kinds of intention based on a systematic relation between the exercise of executive functions and a certain kind of content is the following. The content of intentions for the present has to include indexicals concerning objects to be acted on-for example, that rock (Pacherie 2006; Mylopoulos and Pacherie 2017)—or pragmatic representations, namely representations of specific possibilities for action-for example, a climbable rock (Nanay 2013). By contrast, the content of an intention for the future may or may not include indexicals or pragmatic representations. The rationale behind this is the idea that a content that includes indexicals or pragmatic representations is necessary for the performance of executive functions. However, it can be shown that it is not.

Consider an alternative example in which Wilma settles on the course of action of going shopping for groceries. This is enough to get her to walk and leave the house. The details of which route she is going to take, or even of where she will shop for groceries, will be settled later, but the intention of going shopping for groceries does trigger her action and sustain it until she has completed her errands (unless she changes her mind).
The intention of going shopping for groceries includes neither object indexicals nor pragmatic representations, and yet is apt to trigger and sustain a certain course of action. ${ }^{9}$ There is no straightforward relationship between indexical content or content including pragmatic representations on the one hand and the exercise of executive functions on the other hand..$^{10}$ Therefore, some versions of the notion of intention for the present conflate functional and content-related aspects.

\section{The Hierarchical Theory: HiERARCHICALly ORDERED INTENTIONS OF JUST ONE KIND}

I am now going to put forward a theorythe Hierarchical Theory-that aims to do justice to the phenomena motivating Dual Theories while not falling prey to the aforementioned criticisms.

Both the Hierarchical Theory and Dual Theories aim to answer the following question: how should we account for the planning and performance of a bodily action in terms of the agent's intentions? Dual Theories maintain that a subject will plan and perform an action by means of different kinds of intention: specifically, intentions for the future, which have planning functions, and intentions for the present, which have executive functions. On the basis of the results of section 4.1 , if intentions for the future and intentions for the present are conceived as having the same content, they should be integrated into just one kind of intention. Therefore, in the Hierarchical Theory, from the temporal point of view some intentions will straddle the boundary between before and after action onset. If intentions for the future and intentions for the present are conceived as having different contents, on the basis of the results of 4.2 , they should be replaced by different token intentions of just one kind, each having both functions. The Hierarchical Theory incorporates these results, and has it that a 
subject will plan and perform an action by means of intentions of just one kind, which have both planning and executive functions.

Another question that some Dual Theories attempt to answer is: how do intentions contribute to a subject's representation of their action in greater detail over time? As I mentioned before, many Dual Theories (but not all: cf. Bratman 1987; Pacherie 2006; Mylopoulos and Pacherie 2018) have emphasized the time just before action onset as especially important for the formation of intentions with a more detailed content. This, however, is not warranted: as discussed in section 5.1, a more detailed representation of an action may take place at any point in time, and an action may be represented in greater detail several times.

Here is where the notion of hierarchy comes into play. Incorporating the results of section 5.1, the Hierarchical Theory has it that the process of forming additional token intentions with increasingly detailed contents may occur at any point in time, rather than just around action onset, and typically more than once. I thus suggest that a subject's representation of their action in greater detail is accounted for in terms of many different token intentions, which represent an action in different degrees of detail. ${ }^{11}$
Now, working on the assumption that, at any given point in time, a subject has several token intentions representing their action in different degrees of detail, these intentions are subject to a natural ordering. Developing an insight by Anscombe (1957), I propose that different token intentions may be ordered hierarchically in such a way that the intention to $a$ will lie above the intention to $b$ if and only if $a$ can be done by $b .^{12}$ For example, suppose that one intends to have something to drink. After a moment's reflection, on the basis of this intention, they will form the intention with the more specific content to drink champagne. Now, since having something to drink can be fulfilled by drinking champagne, the intention to have something to drink and the intention to drink champagne may be ordered hierarchically so that the former lies above the latter. By the same token, the intention to drink champagne will lie above any intention with an even more detailed content-for example, the intention to pick up a glass of champagne from a tray that is being passed around (see Fig. 1).

This is why the Hierarchical Theory is so named: it features several token intentions of the same kind that are hierarchically ordered on the basis of the criterion just given. This

\section{ACTIONS}

having something to drink

by

drinking champagne

by

picking up a glass from a tray

\section{INTENTIONS}

intention to have something to drink

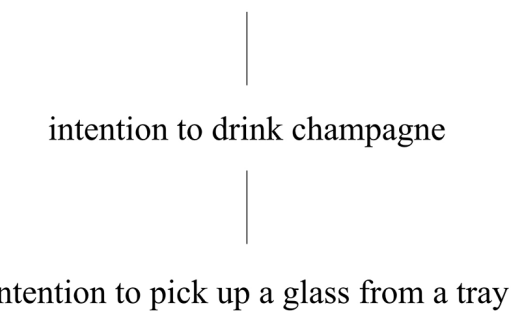

Figure 1. Different token intentions may be ordered hierarchically on the basis of the following principle: the intention to $a$ lies above the intention to $b$ if and only if $a$ can be done by $b$. 
hierarchical ordering reflects relationships of motivation and constraint among different token intentions. Specifically, token intentions higher up in the hierarchy motivate the formation of token intentions lower down in the hierarchy, and impose constraints on their formation (in line with what has also been observed by, for instance, Bratman 1987; Pacherie 2006; Wu 2011; Shepherd 2015). For example, the intention to have something to drink imposes constraints on which intentions are apt to fulfil it: the intention to drink champagne is apt to fulfil it (insofar as one may have something to drink by drinking champagne), but the intention to eat a canapé is not.

In section 5.2, it was observed that the notion of intention for the present featuring in some Dual Theories conflates temporal, functional and content-related aspects. The Hierarchical Theory separates these aspects on the grounds that there is no straightforward relation between them. For example, according to the Hierarchical Theory, a given token intention may exercise executive functions simply as long as it exists for the right amount of time. Specifically, an intention can trigger an action if it is formed just before action onset, or it is formed earlier and retained until action onset, and can sustain an action until completion if it is retained until then. The question of whether token intentions with any content may exercise executive functions would take me too far afield, and will therefore be left for another occasion. The point here is simply that the exercise of executive functions is compatible with many different contents, though not necessarily with any content. In particular, as pointed out in section 5.2, the exercise of executive functions does not require a content that is very detailed, or one that includes either object indexicals or pragmatic representations.

Moreover, temporal vicinity to action onset is unrelated to the degree of content specificity of an intention: many different token intentions may be held from just before action onset, regardless of the degree of detail of their content, as was also shown in section 5.2. Conversely, intentions held well in advance of action onset may, for example, include indexicals: I intend to drink that cup of tea (the one sitting on my desk) as soon as I am finished editing this article, which may take another while.

The Hierarchical Theory, in sum, explicitly separates the temporal profile of intentions from their content-related one. The temporal profile of an intention is determined by when intentions are formed and how long they are retained. The content-related profile of an intention is determined by the state of affairs represented by that intention, and illustrated by the place occupied by that intention in a given hierarchy: intentions higher up in a hierarchy have a less detailed content than intentions lower down in the hierarchy. Herein lies another difference with respect to Dual Theories: the latter are hardly ever explicit about a criterion on the basis of which different token intentions should be distinguished. By contrast, the Hierarchical Theory is explicitly committed to the idea that different states of affairs are represented by different token intentions.

\section{Conclusion}

I have examined the influential proposal that two different kinds of intention-intentions for the future and intentions for the present-are required to account for a subject's planning and performance of a bodily action. I have reviewed the main motivations provided by the theories supporting this proposal, which I referred to as Dual Theories, and concluded that they fail to support this distinction.

I have put forward an alternative to Dual Theories, in the form of the Hierarchical Theory. The Hierarchical Theory incorporates a proposal I have offered about the distinctive contributions of intentions to bodily action 
planning and execution-specifically, concerning the functional role of intentions and the individuation of token intentions on the basis of their content. I have argued that this proposal enables us to do justice to the way in which different subjects are committed to different states of affairs.

Furthermore, the Hierarchical Theory takes into account a criticism that I moved to Dual Theories, according to which the notion of intention for the present is either superfluous or ambiguous. This is because many Dual
Theories construe the notion of intention for the present in such a way that temporal, functional and content-related aspects of intentions are conflated. I have argued that there is no straightforward relation among these aspects, and, therefore, these are best kept distinct. Therefore, the Hierarchical Theory does justice to the phenomena that motivate Dual Theories while not falling prey to the criticisms that I levelled against them.

University of Tübingen

\section{NOTES}

The first version of this article was born in conversation with Steve Butterfill, to whom I am grateful for inspiration and careful feedback on subsequent versions. I am very thankful to Hong Yu Wong for extensive helpful feedback on multiple drafts of this article. I benefited from detailed insightful comments by Luca Barlassina, Olle Blomberg, Wayne Christensen, Harold Langsam, Hemdat Lerman, Al Mele, Kourken Michaelian, Bence Nanay, Johannes Roessler, Matt Soteriou and Sandro Zucchi. I am grateful for thought-provoking comments by members of various audiences, including: Adrian Alsmith, Sofia Bonicalzi, Denis Buehler, Patrick Butlin, John Campbell, Dan Cavedon-Taylor, Tom Crowther, Juan-Camilo Espejo-Serna, Mirko Farina, Pete Fossey, Ellen Fridland, Thor Grünbaum, Falk Hamann, Anandi Hattiangadi, Gregor Hochstetter, Angelica Kaufmann, Caleb Liang, Roberta Locatelli, Guy Longworth, Tom McClelland, Christoph Michel, Alex Morgan, Jean Moritz Müller, Myrto Mylopoulos, Krisztina Orbán, Elisabeth Pacherie, Antonia Peacocke, Mattia Riccardi, Hans Roth, Katia Samoilova, Josh Shepherd, Neil Sinhababu, Corrado Sinigaglia, Nicola Spinelli, James Stazicker, Margot Strohminger, Charles Travis, Peter Wiersbinski, Wayne Wu, and two anonymous reviewers at American Philosophical Quarterly. The research behind this article was supported by the Institutional Strategy of the University of Tübingen (Deutsche Forschungsgemeinschaft, ZUK 63), the FWO Odysseus grant G.0020.12N at the Centre for Philosophical Psychology (Universiteit Antwerpen), the Max Planck Society for the Independent Minerva Research Group, Space and Body Perception, led by Betty Mohler, the John Templeton Foundation (ACT Fellowship awarded to Hong Yu Wong), and the Fritz Thyssen Foundation.

1. I will use the shorthand "just before action onset" to mean sufficiently in advance as to be able to cause the action (see Mele 1992).

2. The assumptions that I am about to report are shared within many standard causal theories of action.

3. According to some Dual Theories, intentions for the future are held at $t_{1}$ only (e.g., Searle 1983; Mele 1992). According to others, intentions for the future are held at both $t_{1}$ and at $t_{2}$ (see section 4.2; O'Shaughnessy 1991; Searle 1991; Pacherie 2008). Either way, a temporal difference exists between intentions for the future and intentions for the present insofar as the latter are held only at $t_{2}$.

4. Executive functions in this context are not to be confused with the notion of executive function in psychology. The latter is an umbrella term for a number of cognitive processes-including inhibitory control, working memory and attentional flexibility - that are involved in the control of actions (Gilbert and Burgess 2008). I am thankful to Wayne Christensen for pointing this out. 


\section{4 / AMERICAN PHILOSOPHICAL QUARTERLY}

5. One may think that $S_{1}$ and $S_{2}$ express different intentions. I object to this, based on the idea that $S 1$ and $S 2$ are merely different formulations of one's indexical thought as time passes (Dokic 1996: 180, referring to Kaplan 1989). Likewise, according to Frege (1918/1984), the same thought expressed on Monday by the sentence "Today is a beautiful day" can be expressed by the sentence "Yesterday was a beautiful day" the day after (Dokic 1996).

6. Mele considers the possibility that intentions for the future might evolve into intentions for the present (1992, pp. 167, 179-180). This is not the same as what I am suggesting, insofar as Mele's suggestion is still compatible with intentions for the future and intentions for the present being two token intentions of different kinds. I am grateful to Steve Butterfill for useful discussion on this point.

7. An anonymous reviewer raises the following question: what role does the difference in content between the two token intentions have in this argument? In particular, couldn't it be that, because the two token intentions considered in this example have different contents, they could consequently have different functions? The latter idea can be excluded on the following grounds. As mentioned in section 3 , it is part of the definition of executive functions that these are exercised relative to the way the action is represented-whether, for example, as walking North, or as walking towards Euston Station-i.e., relative to the specific content of the corresponding intention. Intentions with different contents may therefore all be said to exercise executive functions, and to be equal in this respect. An analogous line of reasoning can be provided as far as planning functions are concerned: the fact that two token intentions have different contents simply means that their planning functions will be exercised relative to different contents-for example, the two token intentions will generate different token intentions via meansend reasoning. Here is an illustration: the intention to keep walking North will generate the intention to walk in the direction indicated by the Northern Star, whereas the intention to walk towards Euston Station will generate the intention to look up Euston Station on one's map. But this is consistent with saying that both token intentions - that to keep walking North and the intention to walk towards Euston Station-have the same function, insofar as both have planning functions. The role of the difference in content between two token intentions in this argument is to show the following: even hypothesising that two token intentions have different contents will not lead to the conclusion that they have different functions, because each token intention can be shown to have both planning and executive functions. An alternative way to raise an objection would be to deny that an intention for the future can acquire executive functions simply as a function of time, unless this intention has a content that is very detailed. This idea will be tackled in section 5.2. I am grateful to an anonymous reviewer for inviting me to clarify these important points.

8. I am grateful to Sandro Zucchi for useful discussion on this point.

9. It may be objected that the content of Wilma's intention to go shopping for groceries, in order to be effective, does need to contain an indexical, namely now. This, however, is not an indexical concerning objects, but, rather, time. In section 4.1 I showed that time indexicals do not license positing different token intentions, let alone intentions of a different kind. I am grateful to James Stazicker for useful discussion on this point.

10. I am grateful to Wayne Christensen for helping me bring this point into focus.

11. An anonymous reviewer wonders: why hold this view, as opposed to one in which the content of an already existent intention is progressively filled in? The reason has to do with the reflections introduced in section 4.2: introducing new token intentions, rather than filling in the content of an already existent intention, enables us to do justice to the commitments that different subjects may have to different states of affairs.

12. See Goldman (1970) for a similar ordering of action tokens. 


\section{REFERENCES}

Alston, William P. 1974. "Conceptual Prolegomena to a Psychological Theory of Intentional Action," in Philosophy of Psychology, ed. Stuart Brown (London, UK: Palgrave Macmillan), pp. 71-101.

Anscombe, Gertrude Elizabeth Margaret. 1957. Intention (Oxford, UK: Blackwell).

Becchio, Cristina, Valeria Manera, Luisa Sartori, Andrea Cavallo, and Umberto Castiello. 2012. "Grasping Intentions: from Thought Experiments to Empirical Evidence," Frontiers in Human Neuroscience, vol. 6, article 117.

Brand, Myles. 1984. Intending and Acting: Toward a Naturalized Action Theory (Cambridge, MA: MIT Press).

Bratman, Michael. 1984. “Two Faces of Intention,” The Philosophical Review, vol. 93, no. 3, pp. 375-405. . 1987. Intention, Plans, and Practical Reason (Cambridge, MA: Harvard University Press).

Dokic, Jérôme. 1996. “The Dynamics of Deictic Thoughts," Philosophical Studies, vol. 82, no. 2, pp. 179-204.

Evans, Gareth. 1982. The Varieties of Reference (Oxford: Clarendon Press).

Frege, Gottlob. 1918. "Der Gedanke. Eine Logische Untersuchung," in Beiträge zur Philosophie des deutschen Idealismus, I (1918-1919), pp. 58-77. Translated as "Thoughts" by Peter Geach and Robert H. Stoothoff, in Collected Papers on Mathematics, Logic, and Philosophy, ed. Brian McGuinness (1984, Oxford: Blackwell), pp. 351-372.

Gilbert, Sam J., and Paul W. Burgess. 2008. "Executive Function,” Current Biology, vol. 18, n. 3, pp. R110-R114.

Goldman, Alvin I. 1970. A Theory of Human Action (Princeton, NJ: Princeton University Press).

Holton, Richard. 2009. Willing, Wanting, Waiting (Oxford: Oxford University Press).

Jacob, Pierre, and Marc Jeannerod. 2005. "The Motor Theory of Social Cognition: A Critique," Trends in Cognitive Sciences, vol. 9, no. 1, pp. 21-25.

Jeannerod, Marc. 2006. Motor Cognition: What Actions Tell the Self(New York: Oxford University Press).

Kaplan, David. 1989. "Demonstratives: An Essay on the Semantics, Logic, Metaphysics, and Epistemology of Demonstratives and Other Indexicals," in Themes from Kaplan, ed. Jospeh Almog, John Perry and Howard Wettstein (Oxford: Oxford University Press), pp. 481-564.

McDowell, John. 2011. "Some Remarks on Intention in Action," The Amherst Lecture in Philosophy, vol. 6, pp. 1-18.

Mele, Alfred R. 1992. Springs of Action: Understanding Intentional Behaviour (New York: Oxford University Press).

Mylopoulos, Myrto, and Elisabeth Pacherie, E. 2017. "Intentions and Motor Representations: The Interface Challenge," Review of Philosophy and Psychology, vol. 8, no. 2, pp. 317-336.

- 2018. "Intentions: The Dynamic Hierarchical Model Revisited," Wiley Interdisciplinary Reviews: Cognitive Science, vol. 10, no. 2, e1481.

Nanay, Bence. 2012. "Action-oriented Perception," European Journal of Philosophy, vol. 20, no. 3, pp. $430-446$.

. 2013. Between Perception and Action (Oxford: Oxford University Press).

O'Shaughnessy, Brian. 1991. "Searle's Theory of Action," in John Searle and his Critics, ed. Ernest Lepore and Robert Van Gulick (Cambridge, MA: Blackwell), pp. 271-287.

Pacherie, Elisabeth. 2006. "Towards a Dynamic Theory of Intentions," in Does Consciousness Cause Behavior? An Investigation of the Nature of Volition, ed. Susan Pockett, William P. Banks, and Shaun Gallagher (Cambridge, MA: MIT Press), pp. 145-167.

- 2008. "The Phenomenology of Action: A Conceptual Framework," Cognition, vol. 107, no. 1, pp. 179-217.

Searle, John. 1983. Intentionality: An Essay in the Philosophy of Mind (New York: Cambridge University Press). 


\section{6 / AMERICAN PHILOSOPHICAL QUARTERLY}

1991. "Response: The Background of Intentionality and Action," in John Searle and his Critics, ed. Ernest Lepore and Robert Van Gulick (Cambridge, MA: Blackwell), pp. 289-299.

Shepherd, Joshua. 2015. “Conscious Control over Action," Mind \& Language, vol. 30, no. 3, pp. 320-344. 2019. "Skilled Action and the Double Life of Intention," Philosophy and Phenomenological Research, vol. 98, no. 2, pp. 286-305.

Sinhababu, Neil. 2013. "The Belief-Desire Model Explains Everything," Nô̂s, vol. 47, no. 4, pp. 680-696.

Wu, Wayne. 2011. "Confronting Many-Many Problems: Attention and Agentive Control," Noûs, vol. 45 , no. 1 , pp. $50-76$. 